In the last part of the Zeitschrift fiur Biologie is an interesting paper by Dr. Camerer, on the locality of the sense of taste, or, as he expresses it, "On the dependence of the sense of taste on the part of the oral cavity irritated." His experiments have been conducted on himself, his wife, a lady friend, and six peasant girls. He employed solution of common salt, quinine, sugar, and sulphuric acid as the exciting agents, and localised their action by pouring a drop or two into a small open tube that was pressed on different parts of the tongue, the determination of the test fluid being required without the subject of the experiment being made acquainted with the nature of the solution used. It is well known that there are three kinds of papillæ on the tongue-the conical, the fungiform, and the circumvallate. Dr. Camerer finds that the sensibility of different parts of the tongue depends essentially on the presence and on the number of the fungiform papillæ. The fungiform papillæ, he finds, are most abundant near the apex of the tongue, they are less numerous at the edges of the tongue, and disappear near the root. There are no papilla on the under surface of the tongue. The latter part he finds to be destitute of gustatory sensibility, whilst the sensibility is most acute when the papillæ are most closely aggregated tcgether. He states also that when a strong solution has been tasted of any of the above substances, the delicacy of the sensibility is impaired for twenty-four hours. Other direct and carefully conducted experiments showed that the gustatory sensibility resided in the fungiform papilla themselves and not in the parts adjoining.

According to the Food Fournal, in Belgium the butchers use laurel oil on the door-posts and window-frames for the purpose of keeping away flies, with great success. So simple a contrivance would be a great boon to the habitues of our eating-houses and confectioners, and would be useful to every housekeeper. The emanation from minced laurel leaves is rapidly fatal to all small insects.

Wirt a view further to promote the cultivation of the Rhea fibre, the Viceroy of India has sanctioned an expenditure temporarily of 8l. per month, at Shaharumpore and at Dehra Dhoon, a hill station.

TIIERE are now in London specimens of iron manufactured for the first time in Peru by the Peruvian Government Commission from magnetic iron ore, found within twenty miles of Lima, and from fair an!hracite taken from a seam sixty fect thick at sixty miles from Lima. The Government is awaiting the development of the railways now in progress. Renewed efforts are being made to enlist English capital in the restoration of the silver mines.

MR. ADAMS, the Secretary of our Legation in Japan, has been rendering good service in doing all he can to protect the silkworm in those countries by his influence and advice, which are willingly received. At the last advices he had returned from a lengthened tour in the interior, on which he will report. In Japanese are some illustrated works on silk culture,

\section{ON CERTAIN PRINCIPLES TO BE OBSERVED IN THE ESTABLISHMENT OF A NATIONAL MUSEUM OF NATURAL HISTOR $Y^{*}$}

T having been now finally determined that the Natural

History collections of the British Museum shall be removed from their present site to South Kensington, to form the nucleus of a National Museum of Natural History, $\dagger$

* Read before Section $D$ at the meeting of the British Association a Liverpool, on September $x 6,1870$

+ On the $3^{\text {rd }}$ of August last a vote of $6,000 l$. was proposed in the House of Commons by the Chancellor of the Exchequer tc clear the ground "fo the erection 0. a Natural History Museum" on the sige of the International Exhibition at South Kensington, and carried, after a division. it appears to me that the principles upon which the proposed new institution are to be established and conducted are well worthy of the special and most serious attention of the British Associaiion for the Advancement of Science. The inauguration of a National Museum of Natural History by one of the nations that have contributed most largely to the advancement of the natural sciences, is an event that is not likely to recur verv often. If the opportunity thus presented be properly taken advantave of, and the new institution started uion sound principles of administration and arrangement, there can be no doubt that a most material impetus will be given to the progress of natural science in this country.

Under these circumstances I think I need hardly apologise for troubling the section with a few remarks upon certain points which appear to me to be most essential to be observed in the eitablishment of a National Museum of Natural History. These, I trust, will at all events provoke discussion, and induce some of the many distinguished naturalists present at this meeting to turn their attention to this most important subject *

The energies of our rulers, es:recially in these troubled times, are too fully occupie.l with ordinary politics to allow them to bestow much care on such a matter, and unless it be forced on their attention by the British Association, or in some other authoritative manner, the result will be, I fear, that the system of administration now followed in the British Museum as regards the Natural History collections. will be transplaned along with the collections themselves, and the excellent opportunity of a grand reform, which may never again prtsent itself, will be utterly wasted $t$

The remarks which I pro:rose to offer to the section on this subject may be divided into three hrads. First. I will say a few words concerning what appears to me to be the best mode of government of the proposed National Museum of Natural History. S condly, I will speak of the form of building which in my opinion ought to be aropted; and lastly, of the arrangement of the collections within that building.

I. Of the form of Government of the National Museum of Natural History.

On this part of my subject I shall make but few remarks, having regard to the fact thit, in common with many other of my fellow naturalists, 1 strong y comınitted myself on this point some years ago. and have in nnwise changed my views since that period. In the memor al, of which l hold a co;y in my hints, and uhich was presented to the Chancellor of the Exchequer in i 8:6 having been signed by 25 leading members of the Royrl, Linn an, Geological, and Zonlogical Sucieties, it will be fuund to be stated that in our op'uion the chief adminisrration of the National Museum of Natural History sh uld be entrusted to one officer, who shill be immediately responsible to some member of the Government. Tho ie who are acquainted with the present mude of adminssiration of the Natural History collections in the British Museum wI 1.1 am sure, readily agree to thi i proposed reform It will be recollected that the governm $n t$, ff the British Muse um is vested by Act of Parliament in a body of fifty trustees, consisting principally of great ufficers of state. and of nominees of certain families whose ancestors have contributed to the heterogeneous contents of that buil ing. Amongst these fifty trustees there are but two or thice that are in any wise interested in Natural History. Their secretary and

* For account of this discussion see p. 465 .

+ In the "bill to entble the lrustees of the Rritish Museum to remove portions of their collection;" " prepared and brou :ht in by the Chiance'lor of the Exchequer in I862, it was I roposed to be ellacted that th: trusters m.ght remove the natural history colle tions to Sonth Kensingtun and certain pictures to the National Gallery. Mut. in a stlbs: quent clause, it was proposed to be added that "except $2 n$ s" far as zuas therein before expressed. nothing therein contained should affect the rights, fowvers, dutips, nr obligations of the trustees of the Brit sh Min.senn." At that ime, herefore. is was clearly intended to co.stinu: the rule of the trustees over the watura history collections when reutoved to Suuti Kensisigton. 
chief executive officer is the present principal librarian, with whose great literary qualifications for his position every one is well acquainted, but who would not, I am sure, claim for himself in any sense the name of a naturalist. It will thus be seen that the actual government of our Natural History collections is at present vested in persons who have no special qualifications for the task. But, it may be said, there is the Superintendent of the Natural History collections, and the keepers of the various departments into which they are divided-have they nothing to do with the administration? To this I reply, very little indeed, unless their advice is asked, or unless they choose to offer it. And, in the latter case, they can only address the trustees through the secretary, who is the only official present at the meetings of the trustees, and in whose hands, therefore, the administration of the Natural History collections is practically vested. This objectionable form of government, we think, ought to be replaced by appointing a director of the proposed new institution. "immediately responsible to one of the Queen's Ministers." This simple form of administration has been most successful in other scientific institutions, such as the Kew Gardens and Herbarium, and the Royal Observatory, and we believe it would be the best in the present case. It might, however, be advisable to give the Director of the National Museum of Natural History a board of advice, composed of the heads of the principal departments into which the Museum is divided. $O r$ another mode of softening the despotism would be to appoint a board of visitors, consisting of distinguished naturalists. These might be delegates from the principal scientific societies of the country, each of whom would be specially bound to see that the particular branch of science, to the advancement of which his society is devoted, received its fair share of attention.

As regards the subordinate appointments in the Natural Museum of Natural History, these ought to be made, if not on the nomination of the director, at least not without his full sanction and approval. The director, being held responsible for the well-doing of the whole establishment, should certainly be allowed to select his own officers more or less directly. It is well known that some of the appointments made by the trustees in the departments of Natural History in the British Museum have been, to say the least of them, in no wise felicitous, and that in one case at least great public scandal has been caused by the notorious incompetence of the person nominated. It is in vain to address remonstrances to a body of irresponsible trustees, but if the director is required to sanction every nomination, we shall know to whom to apply in case of any appointment not being up to the mark.

\section{Of the form of Building of the National Museum} of Natural History.

In discussing the form of building best adapted for a great National Museum of Natural History, let us begin by considering the principal classes of persons for whose accommodation it is or ought to be constructed. These are -

I. The public at large, who go there to get a more or less general notion of the structure of natural objects and of their arrangement in the Systema Natura.

2. The students who use the Museum for scientific purposes.

3. The officers of the institution, whose business it is to amass and arrange the collections.

In the opinion of most members of parliament apparently especially of those who represent metropolitan constituen cies, the first of these three classes is that whose accommodation ought to be first considered in the present case. In my opinion, and probably in that of most of those here present, the National Museum of Natural History ought to bo constructed primarily for the accommodation of the third if the three classes. For, unless the officers of the institution have ample space and opportunity to examine and arrange the collection, it is obvious that neither the public nor the special student can be benefited thereby. At the same time J do not think that the public ought to be utterly excluded from their Museum four days in every week, as is now the case, and I therefore put it forward as an axiom that some system of construction of the New Museum should be adopted whereby the public can be admitted all day and every day to view the collections without interfering with the scientific work of the establishment or with the special examination of objects by students. There is, so far as I know, only one plan by which this object can be carried out-namely, by arranging the exhibited objects in large wall-cases, to which access is obtainable from the back by doors opening into workrooms adjoining the exhibition room. In this way any ordinary object can be removed out of the series into the adjoining work-room, and returned to its place without disturbing the public in front of the cases, just as any article can be taken out of the shop-windows in Regent Street without interfering with those who are looking into them from the pavement outside. This system of exhibition would be attended by the further very great advantage that the glass cases may be hermetically sealed on the side towards the public, and the ingress of dirt and dust thus prevented. Those who are acquainted with the filthy state of the specimens in the public galleries of the British Museum, in spite of frequent cle insings inflicted upon them, will readily appreciate the mexit of this plan.*

This collocation of the exhibition galleries and corresponding working-rooms being insisted upon as of primary importance, the general form of the building must depend somewhat upon the site on which it is to be placed. My own belief, however, is that a hollow square, or something nearly approaching that form, will in many ways be most convenient for a National Museum of Natural History, and the sketches which I now exhibit, which have been prepared for me by my accomplished friend Mr. Osbert Salvin, will serve to show the general plan of arrangement which I propose. The building might be of three or four stories, since, in the system of exhibition which I advocate, it would not be necessary to have top-lights. The basement, which might be partly below the surface, would be dedicated to taxidermy and to rooms for unpacking; storage, and mechanical work of all sorts. In the outer galleries running round the whole length of the ground story, I should propose to arrange the entire series of vertebrates from the highest mammal to the lowest fish. The specimens, according to the system already spoken of, would be placed in hermetically sealed glass cases along the inner walls of the galleries. The inner series of rooms surrounding the interior of the hollow square would be the working-rooms for the officers of the museum and the students of natural history, and would communicate with the glass cases on the inner side of the outer galleries. Each set of working-rooms would, of course, be in immediate apposition to the glass cases containing the corresponding series of exhibited objects. The lights to these working-rooms would be furnished from the inner sides of the hollow square.

In the first story of the building I should propose to arrange the series of invertebrate animals in exactly the same way, with the rooms for officers and students immediately adjoining them on the inner side.

The third story might contain the botanical and mineralogical collections, and perhaps certain others which it might not be possible to introduce into the general series, unless room could be found for these collections in the second story. * In an admirable article on this subject in NATURE, for May 26,1870 ,
Prof. Flower has attributed the original invention of this mode of exhibition Prof. Flower has attributed the original invention of this mode of exhibition
to myself, I having first brought it under his notice. It appears, however, to myself, I having first brought it under his notice. It appears, however, from a subsequent communication to NATURE by Prof. Hower (June 2, 1870), that the same plan had been already proposed ly Dr. Hooker in the (not the original inventor of this 749. I can only, therefore, clain to 
In a circular building, the centre of the hollow square, I should propose to place the library above and lecturetheatre below. The library might be connected by light iron galleries with the different working-rooms, so that the students of every department would have equally ready access to it.

Such is a slight outline of the kind of building I would propose for a National Museum of Natural History. It is, of course, a mere sketch, and there would be, no doubt, many difficulties in the details to be surmounted, but none, I think, such as an experienced architect would not be ab.e to overcome. The advantages of this plan would be :-

I. The museum might be opened to the public every day without interfering with the scientific work of the establishment or of the students. Under the present arrangement, the collections are only open two or three days in the week, during which scientific work is suspended, as regards all objects in the public galleries.

2. The exhibited specimens would be much better protected from dirt and dust than they are in cases opening in front.

3. The exhibition of the whole series of organic beings in one continuous range of galleries would be much more instructive to the public than any system in which (as in the British Museum) they are dispersed about in different rooms.

4. The library being in the centre, would be equally accessible from any one of the working-rooms surrounding the interior of the hollow square.*

III. Of the Arrangement of the Collections in the National Museum of Natural History.

The remarks which I have already made under the previous head will have served to show the section that I am an advocate of what has been called the "typical," but what it would be better, perhaps, to call the "representative" system of arrangement of the Natural History collections. Nor am I able to understand how any reasonable person can seriously maintain that every object in a National Museum of Natural History ought to be exhibited to the indiscriminating public. In accordance with the views of the memorialists of $1858,+$ who may be considered as having inaugurated the reform in our Natural History collections which $I$ hope to see shorily carried out, the collections should be primarily separated into three series : $(a)$, objects for public exhibition; $(b)$, objects for private study. The class $a$, which is to be arranged in the public galleries behind the hermetically sealed glass cases, should embrace a very full and well-selected series of representatives of the principal forms of every class. In some cases it may be necessary to place in this category examples of every species of a group, in others only a selection of each genus or of each family. Every specimen exhibiting the external form in this series should be carefully prepared and mounted in a natural attitude. The representative species of the group having been selected, specimens of both sexes and of all ages should be placed in the series, as likewise examples of variation, if any such are known. The skeleton and other preparations of the internal structure should be added, as also the eggs and nests in the case of birds, and examples of corresponding structures in other classes. In short, the utmost endeavours should be made to illustrate, by preparations, models, and drawings, the life-history of the selected "representative," in as complete a manner as possible. To every

* A great deal has been said by those who have advocated the retention of the gratural History co!lections in their present site, about the importance of of the National Library. It is, of course keeping up their comoval will necessitate the acquisition of a special Library ob or me meum. I believe, however, that a library of Natual of the kind, sulfiently difficulty and at a comparatively small cost, and t: at when formed, it will be of much greater use for those working at the collec when for the British Museum. I tionsthan the presibed that the library of the British Museun is only must be afor the use of the officers. The books cannot be brou tht to the avaliable for the books by ordinary students.

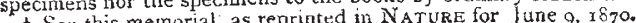

exhibited specimen should be attached a printed label, giving its scientific and popular name, locality, and origin, and some short explanation regarding its chief peculiarities and most noticeable points of interest. There can, I think, be no doubt whatever that a small but wellselected series of any branch of the kingdom of nature, arranged after this method, would be of much greater interest and much more instructive to the public at large, than ten times the number of objects arranged according to the present fashion of the British Museum.

On the other hand, the great mass of the collections (b) intended only for the private examination of experts should be treated after a very different fashion. In this division of the collections, the object is to arrange specimens in as small a space as possible, and, at the same time, in the most convenient manner for easy examination. The work-rooms immediately adjoining the part of the public galleries appropriated to division $a$ of any class, will, of course, be devoted to the reception of division $b$ of the same class, so that the whole $a$ and $b$, being separated only by the partition-wall at the back of the glazed cases, which will be pierced by frequent doors, will practically form but one collection. In these work-rooms, moreover, should be assembled together the whole of the specimens relating to the particular class to whicl they are devoted. In the British Museum, according to the present system, the mounted specimens are in one room, the skins in a second, the skeletons in a third, and the spirit-preparations in a fourth. So that, in order to make a complete examination of a small mammal, for instance, it may be necessary to go to four or five different parts of the build. ing, ranging from the galleries to the cellars, and from the extreme north-east corner of the former to the furthest south-west corner of the latter. In the new National Museum of Natural History, it is to be hoped, this inconvenience will be remedied by the entire amalgamation of the various collections of skins, mounted specimens, spirit-specimens, and skeletons, into one uniform series. Besides the greater convenience of this mode of arrangement, another obvious advantage will be that the future student will be induced to devote his attention rather to the whole structure of the organism than to confine it to one particular part. If bird-cabinets were accompanied by skeletons and corresponding specimens in spirits, there can be no doubt that a much more perfect system of ornithology than any that we have yet attained to would be quickly arrived at. Our new national museum must take the lead in this great reform, and set an example to other collections. In the same way, as every naturalist will allow, our conchological brethren will lose nothing by having the soft bodies of the mollusca close at hand to aid them in their investigations on the form of the external sheli. There may be, of course, some exceptional cases in which it will be practically impossible to adopt this course, but, as a general rule, the principle should be insisted upon that every specimen, of whatever nature it may be, should be located in the rooms devoted to the reception of the class to which it belongs, and should be placed as nearly as possible in immediate apposition to its nearest natural allies.

To carry out these principles to their legitimate issue, I do not hesitate to support the view put forward by Prof. Flower* and other naturalists, that the palceontological department of the British Museum, as at present constituted, ought to be totally abolished, and its contents distributed amongst the zoological and botanical collections, so that extinct forms may be studied in association with their nearest living representatives. The arguments in favour of this plan are, I think, unassailable, and although some little difficulties may be met with in carrying it out, there are none, in my opinion, that may not be overcome by judicious treatment. There is no doubt, I believe, that the progress of palæontology and palæophy-

$$
\text { * See Nature for May 28, I87o. }
$$


tology has been much retarded by the neglect of the students of the extinct forms of animal and vegetable life to make themselves sufficiently acquainted with the structure of the corresponding forms now in existence. So long as fossils were looked upon as the protucts of numerous successive and independent creations, there might have been some excuse for this mode of dealing with them. But now that we regard animated nature, past, present, and future, as one and indivisible: now that we acknowledge the stream of lile, since its first appearance on this planet, to have been unbroken and continurus, let us exhibit its products, whether existing or extinct, in one continuous and unbroken series. The structure of an extinct organism can only be correctly undersiood after study of the nearest allies at iresent in existence. The best palæontologist must be he that has deduced his knowledge of extinct beings from comparison of thrir remains with the corresponding parts of those now alive. Those who ap- preciate these truths will not fail to allow that the proposed amalgamation of the palæontological collection in the general series in the new Museum of Natural History, will be a decided step in advance, and one imperatively called for in the present state of natural science.

I have now, I think, touched upon some of the principal points on which changes are required in our present system of treatment of the collections of natural history belonging to the nation. It would be easy to go into further particulars in which reforms are needed. Especially I might call attention to the inadequacy in point of numbers of the present staff of officers in some of the Natural History departments of the British Museum, the insuf. ficiency of the yearly sum allowed for acquisitions, the vexatious regulations concerning the examination of specimens, and the miserably insufficient accommodation for private study. But all these things we may well hope to see altered in a new institution, and I will not

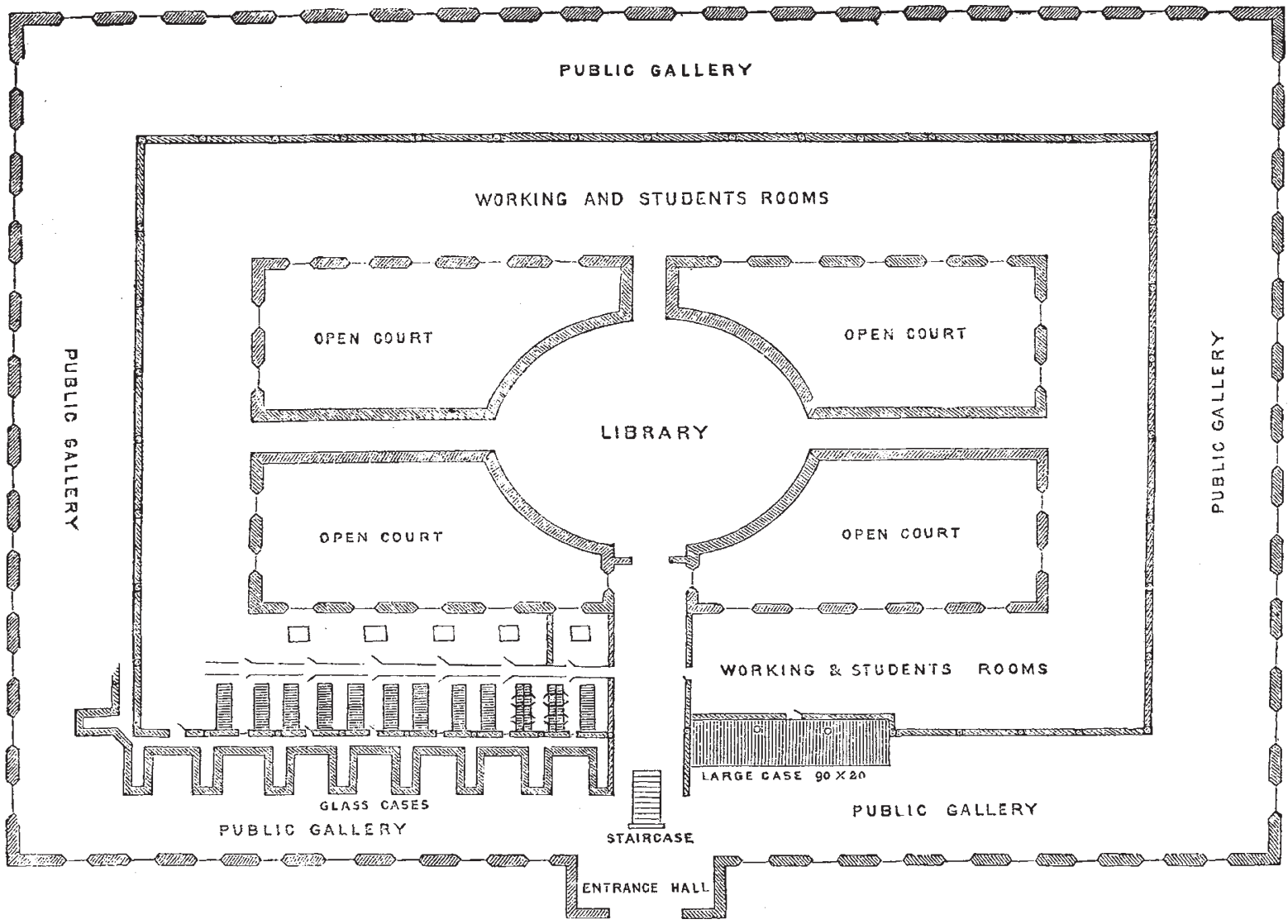

take up time by enlarging upon them. In conclusion, / arranged in rooms immediately adjacent to the public however, I will reafitutate the principal topics touched on in the follow iny pro, sositio"s, which I trust the mem bers of the British Association will agree with me in putting forward as the "platform" of reforming naturalists.

I. The administration of the New Museum of Natural History should be rested in a director, who should be immediately resporisib'e to ine of the Queen's Ministers.

2. The collections should be primarily divided into two series: $(a)$ those intended for public exhibition; $(b)$ those reserie $a$ for piivate study.

3. Tue collections $a$ (for public exhibition) should be arsanged in their natural order, in one continuous series of yatleries, so as to give the best possible general idea of the principal forms of life, and of their arrangement according to the natural system.

4. The collections $b$ (tor private study) should be galleries, in such a manner that the corresponding portions of $a$ and $b$ should practically form but one series, and that the private student should have access at all times to objects in the public galleries.

5. A complete Library of Natural History should be furnished for the special use of the institution, and be placed in some central portion of the building, equally accessible to all departments.

6. The collection of osteology, the spirit-preparations, the skins in store, the series of British animals, the collection of "nests and nidamertal structures," and all other subordinate collections, should be amalgamated in the general series.

7. The collections of the Palæontological Department should likewise be amalgamated with the general series. P. L. SCLATER 